\title{
Prevention of Alveolar Osteitis following Third Molar Surgery
}

\author{
Amir H Nejat* and Adriana Wilson \\ Department of Prosthodontics, Louisiana State University Health Science Center-New Orleans, USA
}

Received: June 04, 2018; Published: June 12, 2018

*Corresponding author: Amir H Nejat, Department of Prosthodontics, Louisiana State University Health Science Center-New Orleans, 1100 Florida Ave, Room \#3339, New Orleans, LA 70119, US

\begin{abstract}
Alveolar osteitis (AO) is one of the most common complications after third molar surgery. Various risk factors has been determined as the etiology of AO. In addition, different preventive measures with promising outcome have been provided by researchers. The aim of the present review is to provide the most recent preventive measures to reduce the risk of developing AO following third molar surgery.
\end{abstract}

Keywords: Alveolar Osteitis, Dry Socket, Third Molar, Extraction

Abbreviations: AO: Alveolar Osteitis; CHX: Chlorhexidine; PRF: Platelet-Rich Fibrin

\section{Introduction \& Discussion}

Alveolar osteitis (AO) is one of the most common complications after third molar extraction. AO is also called dry socket as it is marked with loss of blood clot in the extraction socket in addition to progressive pain starting 1 to 3 days after surgery, halitosis, regional lymphadenitis, and foul taste [1]. Although it is a selflimiting postoperative complication and resolves within 5 to 10 days without any treatment, it affects patient's quality of life in this period. In addition, it may require up to 4 dental visits until complete resolution [1-3]. The etiology of AO is not fully understood; however, two theories are widely accepted for possible cause of AO development. Birn [4] in 1973 found that the fibrinolytic activity was increased in sockets developing AO. This activity can interfere with the integrity of the blood clot and lead to clot loss in the extraction socket. The other theory is bacterial activity of the site which lead to lysis of the blood clot and ultimately loss of the clot [2].

The rate of AO development varies between $5 \%$ and $30 \%$ in different publications. Due to the high rate of this complication after third molar extractions and surgeries, prevention of this complication has been the focus of number of publications in this field. Based on the published papers, various risk factors have been outlined in development of AO including age, gender, menstrual cycle and oral contraceptives in women, periapical infection in the area, difficulty of the surgery and amount of trauma during the surgery, impaction pattern of the third molar, surgeon's experience, amount of socket irrigation during the surgery, and number of anesthetic cartridges used to anesthetize the patient [5-10]. One of the main challenges in this field is to prevent $\mathrm{AO}$ after third molar surgery. Based on the literature, there are number of ways to reduce the risk of development of AO:

\section{Antibiotics}

In accordance with the bacterial theory of AO development, it has been shown that systemic antibiotics including penicillin, clindamycin, and erythromycin, and metronidazole can reduce the rate of AO development after third molar surgery [11]. However, Fazakerley and Field [3] recommended that the systemic antibiotics should be restricted to immunocompromised patients and in case of malaise and lymphadenopathy, and cases with history of AO.

\section{Chlorhexidine (CHX) Mouthwash}

It has been shown that rinsing with $\mathrm{CHX}$ can significantly reduce the risk of developing AO. However, it should be noted that rinsing should be postponed to second day after surgery as rinsing during the first day can dislodge the clot and increase the risk of developing AO [12]. While AO develops within the first day to third day after surgery, mouth-rinse could have less impact in comparison to other forms of CHX. Hence, gel form of CHX has gained popularity [13].

\section{CHX Gel}

The gel form has the advantage of releasing the active agent gradually and in a longer period. Hence, the gel form improves the 
bioavailability of the active agents. As mentioned above, mouthwash cannot be used during the first postoperative day while the gel form makes the CHX available right after the surgery. Numerous studies have identified the advantage of CHX gel in reducing the rate of postoperative complications after third molar surgery including AO [13].

\section{Platelet-rich Fibrin (PRF)}

PRF is the 2nd generation of platelet concentrates. PRF contains different types of immune cells and cytokines [14]. In addition, due to the structural strength, PRF can be used as a membrane to cover the wounds and extraction sockets. It gives the surgeon the ability to suture it to the extraction socket after surgery [15]. It can also improve healing process with providing a scaffold for the tissue to grow on. It has been shown that application of PRF after the third molar surgery can reduce the risk of developing AO $[15,16]$.

\section{Combination of PRF and CHX}

Recently study published by Eshghpour et al. [15,17] reported that the risk of development of AO can be lowered to the level of non-surgical extractions (rate of AO in non-surgical extractions is $1-4 \%$ ) by application of CHX to the extraction socket after surgery and covering the extraction socket by PRF. In this case, they found that the rate of $\mathrm{AO}$ was $4.06 \%$ while it was $21.95 \%$ in control group. They attributed this significant improvement to the point that CHX reduce the bacterial activity and PRF covers the socket and prevents the dislodgment of the blood clot. With this method, both described theories of AO development (bacterial and blood clot loss) would be inhibited [17].

\section{Timing of the surgery}

The study published by Eshghpour et al showed that menstrual cycle affects the risk of developing AO. They observed that the rate of $\mathrm{AO}$ was significantly less when the surgery was performed during the menstrual period in comparison to mid-cycle (when the hormones are at their peak). Hence, managing the timing of the surgery with the menstrual cycle of the patient can be a preventive measure for $\mathrm{AO}$ development after third molar surgery. In addition, they showed that in oral contraceptive takers, the rate of $\mathrm{AO}$ can be reduced by having the surgery scheduled during the menstrual period [9].

\section{Conclusion}

Hence it can be concluded that $\mathrm{AO}$ is a preventive postoperative complication after third molar surgery and by application of effective prevention modalities it would be possible to reduce the risk of its development to the level of risk in normal tooth extractions.

\section{References}

1. Osborn TP, Frederickson G, Small A, Torgerson TS (1985) A prospective study of complications related to mandibular third molar surgery. J Oral Maxillofac Surg 43(10): 767-769.
2. Noroozi AR, Philbert RF (2009) Modern concepts in understanding and management of the "dry socket" syndrome: Comprehensive review of the literature. Oral Surg Oral Med Oral Pathol Oral Radiol Endod 107(1): 30-35.

3. Fazakerley M, Field EA (1991) Dry socket: A painful post-extraction complication (a review). Dent Update 18(1): 31-34.

4. Birn H (1972) Fibrinolytic activity of alveolar bone in "dry socket" Acta Odontol Scand 30: 23-32.

5. Bortoluzzi MC, Capella DL, Barbieri T, Marchetti S, Dresch CP, et al. (2012) Does smoking increase the incidence of postoperative complications in simple exodontias. Int Dent J 62(2): 106-108.

6. Eshghpour M, Nejat AH (2013) Dry socket following surgical removal of impacted third molar in an Iranian population: Incidence and risk factors. Niger J Clin Pract 16(4): 496-500.

7. Sisk AL, Hammer WB, Shelton DW, Shelton DW, Joy ED, et al. (1986) Complications following removal of impacted third molars: The role of the experience of the surgeon. J Oral Maxillofac Surg 44(11): 855-859.

8. Halabi D, Escobar J, Munoz C, Uribe S (2012) Logistic regression analysis of risk factors for the development of alveolar osteitis. J Oral Maxillofac Surg 70(5): 1040-1044.

9. Eshghpour M, Rezaei NM, Nejat A (2013) Effect of menstrual cycle on frequency of alveolar osteitis in women undergoing surgical removal of mandibular third molar: A single-blind randomized clinical trial. J Oral Maxillofac Surg 71(9): 1484-1489.

10. Kolokythas A, Olech E, Miloro M (2010) Alveolar osteitis: a comprehensive review of concepts and controversies. Int J Dent 249073.

11. Delilbasi C, Saracoglu U, Keskin A (2002) Effects of $0.2 \%$ chlorhexidine gluconate and amoxicillin plus clavulanic acid on the prevention of alveolar osteitis following mandibular third molar extractions. Oral Surg Oral Med Oral Pathol Oral Radiol Endod 94(3): 301-304.

12. Teshome A (2017) The efficacy of chlorhexidine gel in the prevention of alveolar osteitis after mandibular third molar extraction: a systematic review and meta-analysis. BMC Oral Health 17(1): 82.

13. Torres Lagares D, Gutierrez Perez JL, Hita Iglesias P, Magallanes Abad N, Flores Ruiz R, et al. (2010) Randomized, double-blind study of effectiveness of intra-alveolar application of chlorhexidine gel in reducing incidence of alveolar osteitis and bleeding complications in mandibular third molar surgery in patients with bleeding disorders. J Oral Maxillofac Surg 68(6): 1322-1326.

14. Dohan DM, Choukroun J, Diss A, Dohan AJ, Mouhyi J, et al. (2006) Platelet-rich fibrin (PRF): A second-generation platelet concentrate.Part II: Platelet-related biologic features. Oral Surg Oral Med Oral Pathol Oral Radiol Endod 101(3): e45-50.

15. Eshghpour M, Dastmalchi P, Nekooei AH, Nejat AH (2014) Effect of plateletrich fibrin on frequency of alveolar osteitis following mandibular third molar surgery: A double-blinded randomized clinical trial. J Oral Maxillofac Surg 72(8): 1463-1467.

16. Hoaglin DR, Lines GK (2013) Prevention of localized osteitis in mandibular third-molar sites using platelet-rich fibrin. Int J Dent 875380 .

17. Eshghpour M, Danaeifar N, Kermani H, Nejat AH, et al. (2018) Does IntraAlveolar Application of Chlorhexidine Gel in Combination With PlateletRich Fibrin Have an Advantage Over Application of Platelet-Rich Fibrin in Decreasing Alveolar Osteitis After Mandibular Third Molar Surgery? A Double-Blinded Randomized Clinical Trial. J Oral Maxillofac Surg 76(5): 939e1-939e7. 
(C) (i) This work is licensed under Creative

Submission Link: https://biomedres.us/submit-manuscript.php

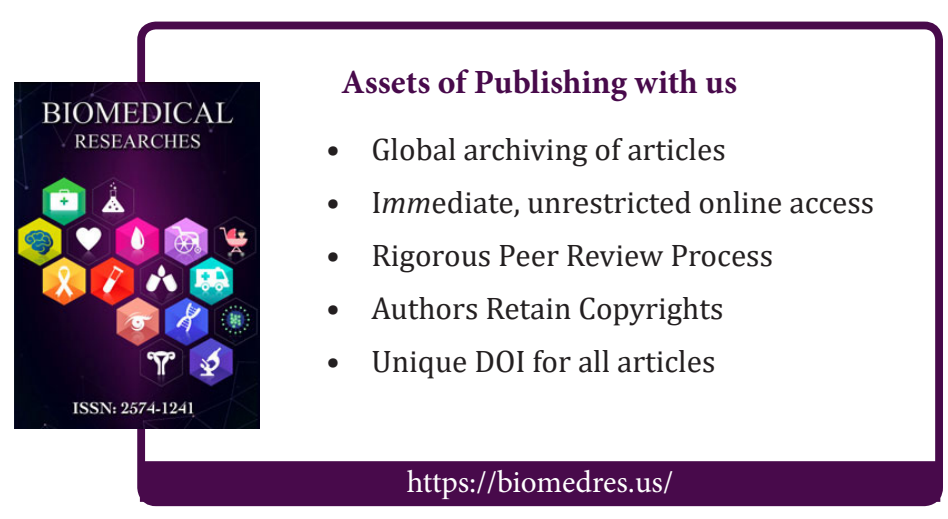

